\title{
Chest Mobility Exercise with Staked Breathing Versus Chest Mobility Exercises with Incentive Spirometery On Chest Expan- sion with Pleural Effusion Patient: A Comparative Study
}

\author{
Minhaj Tahir *1, Tahzeeb Fatima ${ }^{2}$, Devendra Trivedi ${ }^{3}$, Manjit Kumar ${ }^{4}$. \\ ${ }^{* 1}$ Assistant Professor, Department of Physiotherapy, Rama University, Kanpur, Uttar Pradesh, India. \\ ${ }^{2}$ Assistant Professor, Department of Physiotherapy, Rama University, Kanpur, Uttar Pradesh, India. \\ ${ }^{3}$ Assistant Professor, Department of Physiotherapy, Rama University, Kanpur, Uttar Pradesh, India. \\ ${ }^{4}$ Assistant Professor, Department of Physiotherapy, Rama University, Kanpur, Uttar Pradesh, India.
}

\section{ABSTRACT}

Background: Pleural effusion is one of the commonly seen respiratory conditions in India with approximately 1 million people being diagnosed each year. Twenty to forty percent of hospitalized patients with bacterial pneumonia develop pleural effusion. In India unlike western countries, tuberculosis pleura effusion is common. The pleural cavity is involved in approximately $5 \%$ of all patients with tuberculosis. Since there was no literature regarding the effectiveness chest mobility exercise with staked breathing or chest mobility exercises with incentive spirometery in pleural effusion. There was a need to find out as to which approach are the best ones to implement.

Objective: To compare the efficacy of chest mobility exercise with stacked breathing versus chest mobility exercise with incentive spirometery on chest expansion in patients with pleural effusion.

Materialsand Method: 20 patients with pleural effusion were selected by easy sampling and randomly assigned into two groups(10patients each groups). Group A received chest mobility exercises and intensive spirometery and group $B$ received chest mobility exercises and stacked breathing. Both groups were instructed to perform the intervention 3 time per day, 8 to 10 time per session for one week. Chest expansion was measured by thoracic flow cytometry before and after one week of intervention.

Result: In group Achest expansion increase from 2.68 to 2.87 which was statistically significant (P value $<0.0023)$. In Group B the chest expansion increases from 2.94 to 3.09 which was not statistically significant (P value < 0.216).

Conclusion: It was concluded from the result that both chest mobility exercises with intensive spirometery and chest mobility exercise with stacked breathing are equally effective in improving the chest expansion in subject with pleural effusion.

KEYWORDS: Pleural effusion, Chest mobility exercises, Incentive Spirometry, Stacked breathing, Thoracic flow cytometry.

Address for correspondence: Dr. Minhaj Tahir,Assistant Professor, Department of Physiotherapy, Rama University, Kanpur, Uttar Pradesh, India.E-Mail:minhajtahirsmart@gmail.com

Access this Article online

Quick Response code

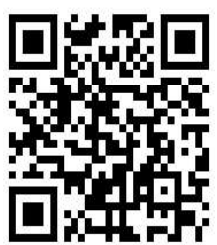

DOI: $10.16965 / \mathrm{ijpr} .2021 .155$
Journal Information

International Journal of Physiotherapy and Research

ISSN (E) 2321-1822 | ISSN (P) 2321-8975

https://www.ijmhr.org/ijpr.html

DOI-Prefix: https://dx.doi.org/10.16965/ijpr

\section{Article Information}

Received: 11 Jun 2021

Peer Review: 15 Jun 2021

Revised: None
Accepted: 13 Jul 2021

Published (O): 11 Aug 2021

Published (P): 11 Aug 2021

INTRODUCTION

A pleural Effusion is accumulation of

excessive fluid in the pleural space, the

Int J Physiother Res 2021;9(4):3949-53. ISSN 2321-1822 
caused by disturbed osmotic or hydrostatic pressure in the plasma [1,2].Under normal condition, pleural fluid is secreted by the parietal pleural capillaries at a rate of 0.01 milliliter per kilogram weight per hour, and is cleared by lymphatic absorption leaving behind only 5-15 milliliters of fluid, which helps to maintain a functional vacuum between the parietal and visceral pleurae. Excess fluid within the pleural space can impair inspiration by upsetting the functional vacuum and hydrostatically increasing the resistance against lung expansion, resulting in a fully or partially collapsed lung.

Various kinds of fluid can accumulate in the pleural space, such as serous fluid (hydrothorax), blood (hemothorax), pus (pyothorax, more commonly known as pleural empyema). When unspecified, the term " pleural effusion" normally refers to hydrothorax. A pleural effusion can also be compounded by a Pneumothorax, leading to a hydropneu mothorax.A pleural effusion may be transudative or exudative. A transudative develops when fluid from the pulmonary capillaries moves into the pleural space. The fluid is thin and watery, containing a few blood cells and little protein. The pleural surfaces are not involved in producing the transudate. In contrast, an exudates develops when the pleural surface are diseased. The fluid has high protein content and a great deal of cellular debris. Exudates are usually caused by inflammation, infection or malignancy [3].

The common transudative causes of pleural effusion are left ventricular failure, cirrhotic liver disease, peritoneal dialysis, hypoalbuminaemia, nephritic syndrome, pulmonary embolism, hypothyroidism, and mitral stenosis, and the common exudative cause are parapneu-monic effusion, malignant neoplasm, pulmonary embolism, rheumatoid arthritis, pancreatitis, autoimmune disease etc [4].

When a pleural effusion has been determined to be exudative, additional evaluation is needed to determine its cause, and amylase, glucose; $\mathrm{pH}$ and cell count should be measured. Red blood cell counts are elevated in cases of bloody effusion (for example after heart surgery or hemothorax from incomplete evacuation). Amylase levels are elevated in cases of esophageal rupture, pancreatic pleural effusion, or cancer. Glucose is decreased with cancer, bacterial infections, or rheumatoid pleuritis. $\mathrm{PH}$ is low in emphysema $(<7.2)$ and may be low in cancer.

If cancer is suspected, the pleural fluid is sent for cytology. If cytology is negative, and cancer is still suspected, either a thoracoscopy, or needle biopsy of the pleura may be performed [5].The most common causes of exudative pleural effusion are bacterial pneumonia, cancer, viral infection, and pulmonary embolism. Other common cause is after heart surgery, when incompletely response that causes exudative pleural fluid. Conditions associated with exudative pleural effusion [6].Parapneumonic effusion due to pneumonia, malignancy, infection, trauma, pulmonary infarction, pulmonary embolism, autoimmune disorder, pancreatitis, Ruptured esophagus, rheumatoid pleurisy, and druginduce lupus. Pleural effusion may also occur through medical or surgical interventions, including the use of medications, coronary artery bypass surgery, abdominal surgery, endoscopic variceal sclerotherapy, radiation therapy, liver or lung transplant, insertion of ventricular shunt as a treatment method of hydrocephalus $[7,8]$, and intra or extra vascular insertion of central lines.

The physiotherapy management of pleural effusion would include breathing exercises, localized expansion exercises, belt exercises; positioning etc [9]. Chest mobility exercises are effective in improving the mobility of the chest wall, trunk, shoulders, increasing ventilation on that side of the chest, emphasizing depth ofinspiration and controlling expiration. These exercises areeffective in improving the chest expansion in subjects withpleural effusion. Study [10]concludes that chest mobility exercises have resulted in betterment ofrespiratory functions such as reduction in dyspnea level andsignificant improvement in chest expansion whenimplementing a specific stretching protocol in complicationssuch as secretion retention and pleural effusion following apercutaneous pig tail nephrostomy 
[11].Incentive spirometery has been found to be appropriate for lungre-expansion following major thoracic surgery [12],but it is not known whether Incentive spirometry can producesimilar kind of re-expansion in subjects with unilateral pleuraleffusion. Also, the Breath stacking technique has shown to beeffective particularly in uncooperative patients followingabdominal surgeries [13] and in mobilizinggreater lung volumes 17 and in achieving and sustaining deepinspiration, even in uncoached patients 14]. But itis not known whether it will have similar effects in patientswith unilateral pleural effusion. Therefore, there exists a needto compare the effectiveness of chest mobility exercises withincentive spirometery and chest mobility exercises with stackedbreathing on the chest expansion in patients with unilateralpleural effusion.

\section{MATERIALS AND METHODS}

The source of data wasLeelamani Hospital, Kanpur. 20 patients with pleural effusion were collected by conveniencesampling. Patients of both genders in the age group of 20-50 years, diagnosed as unilateral pleural effusion with asymmetricalchest expansion were included in the study. However, patients with orthopaedic conditions, hypertension, malignancy, cognitive impairments, and pleural effusion due to transudateconditions like liver cirrhosis, CCF etc. and those who refusedwere excluded.After getting ethical clearance subjects were enrolled in thestudy. Patients with unilateral pleural effusion were recruitedfrom the medical ward of the hospital. Patients were selectedbased on the inclusion and exclusion criteria. Following aninitial assessment the patients were assigned to one of the twogroups by block randomization. After randomizing the patientto one of two groups, before the intervention chest expansion was measured by Thoracic flow cytometry [15].

Basal expansions were determined byusing a tape measure as it is known that pleural effusionaccumulates in the lower zones. Each measurement wasobtained after maximal expiration followed by maximuminspiration and another maximal expiration. Measurements were taken twice and the mean of the two values wasrecorded.Group Areceived chest mobility exercises with incentivespirometry [16] and the AARC [17].Group Breceived Chest mobility exercises with stackedbreathing according to guidelines given by Kisner (Milojeviæ et al., 2003) and breath stacking techniqueexplained by providence care. Both groups were instructed to perform the intervention 3times per day, 7-8 times per session for one week. Thoracicflow cytometry was repeated after one week.Data analysis was performed by SPSS. Alpha value was set as 0.05 . Paired t test was usedto find out significant differences for the chest expansionwithin the groups. Unpaired t test was used to find outsignificant differences for the chest expansion between thegroups.

\section{RESULTS}

Data are mean \pm standard deviation. In group A the meanage was 37.50 and sd was 5.86 and in group B the mean agewas 38.36 and sd is 6.20 which is not statistically significant ( $p$ value greater than 0.631). In group $A$ there were 6 malesand 7 females, in group $B$ there were 7 males and 6 femaleswhich was not statistically significant ( $p$ value greater than 0.604). In group A there were 9 right sided and 4 left sidedpleural effusion and in group $B$ there were 8 right sided and 5left sided pleural effusion which was statistically notsignificant ( $p$ value greater than 0.604 ) In summarydemographic variables were homogeneous between groups.

Table 1:Base line data for demographic variables.

\begin{tabular}{ccccc}
\hline S. No. & Variable & Group A & Group B & P value \\
\hline 1 & Age & $37.50 \pm 5.86$ & $38.36 \pm 6.20$ & $>0.631$ \\
2 & Gender & $6 / 7$ & $7 / 6$ & $>0.604$ \\
3 & Side & $9 / 4$ & $8 / 5$ & $>0.604$ \\
\hline
\end{tabular}

Table 2:Baseline Data for outcome variables.

\begin{tabular}{ccccc}
\hline S. No. & Variable & Group A & Group B & P value \\
\hline 1 & Upper zone & $0.18 \pm 0.41$ & $0.14 \pm 0.22$ & $>0.725$ \\
2 & Middle zone & $0.44 \pm 0.42$ & $0.68 \pm 0.22$ & $>.024$ \\
3 & Lower zone & $0.47 \pm 0.41$ & $0.75 \pm 0.58$ & $>0.110$ \\
\hline
\end{tabular}

Data are mean \pm standard deviation. In group $A$ the mean upper zone chest expansion was 1.29 and sd was 0.41 , and in group B it was 0.14 and sd was 0.22 which was not 
statisticallysignificant ( $p$ value greater than $0.725)$. In group $A$ the mean middle zone chest expansion was 0.44 and sd was 0.42 , and in group Bit was 0.68 and sd was 0.22 which was not statisticallysignificant ( $p$ value greater than $0.024)$. In group $A$ the mean lower zone chest expansion was 0.47 and sd was 0.41 , and in group B it was 0.75 and sd was 0.58 which is not statisticallySignificant ( $p$ value greater than $0.110)$. In summary theoutcome variables were homogeneous between groups.

Table 3:Pre post difference with in group A.

\begin{tabular}{ccccc}
\hline S. No. & Variable & Pre & Post & P value \\
\hline 1 & Upper zone & $0.18 \pm 0.41$ & $0.20 \pm 0.40$ & $>0.053$ \\
2 & Middle zone & $0.44 \pm 0.42$ & $0.46 \pm 0.42$ & $>0.078$ \\
3 & Lower zone & $0.47 \pm 0.41$ & $0.66 \pm 0.41$ & $<.0001$ \\
\hline
\end{tabular}

Table 4:Pre post difference with in group B.

\begin{tabular}{ccccc}
\hline S. No. & Variable & Pre & Post & P value \\
\hline 1 & Upper zone & $0.14 \pm 0.22$ & $0.50 \pm 0.26$ & $<.0001$ \\
2 & Middle zone & $0.68 \pm 0.22$ & $0.71 \pm 0.23$ & $>.003$ \\
3 & Lower zone & $0.75 \pm 0.58$ & $1.06 \pm 0.56$ & $<.0001$ \\
\hline
\end{tabular}

Table 5:Mean difference between groups.

\begin{tabular}{ccccc}
\hline S. No. & Variable & Group A & Group B & P value \\
\hline 1 & Upper zone & $0.20 \pm 0.40$ & $0.50 \pm 0.26$ & $>.056$ \\
2 & Middle zone & $0.46 \pm 0.42$ & $0.71 \pm 0.23$ & $>.020$ \\
3 & Lower zone & $0.66 \pm 0.41$ & $1.06 \pm 0.56$ & $<.080$ \\
\hline
\end{tabular}

However when comparing between groups, the mean increase in upper zonechest expansion in group $A$ was 0.20 with sd 0.40 and in group $B$ it was 0.50 with sd 0.26 which was not statisticallysignificant ( $p$ value greater than 0.056). Mean increase in middle zone chest expansion in group A was 0.46 with sd 0.42 and in group $B$ was 0.71 with sd 0.23 which was not statistically significant ( $p$ value greater than 0.020). Mean increase in lower zone chest expansion was 0.66 with sd 0.41 in group $A$ and in group $B$ it was 1.06 with sd 0.56 which was statistically significant ( $p$ value less than 0.080).

\section{DISCUSSION}

The objective of this study was to compare the efficacy ofchest mobility exercises and incentive spirometer with that ofchest mobility exercises and stacked breathing on chestexpansion in subjects with unilateral pleural effusion. Group Awhich has undergone chest mobility exercises with incentives pirometer has shown statistically significant increase in chestexpansion in the lower zones.
Group B which has undergonechest mobility exercises with stacked breathing has shown statistically significant increase in chest expansion in the upperand lower zones. However, results did not show any statistically significantdifference between group $A$ and group B.A study done byVikram et al who evaluated the effects of chest mobility exercises as an adjunct modality in post operative pulmonarymanagement and concluded that chest mobility exercises canenhance the chest wall elevation, thus increasing expansion [10].

In the present study chest mobility exercises were carried out in both the groups. This could haveresulted in equal improvement within group for lower zonesand since both groups have undergone chest mobility exercisesthere was no difference between groups. Another possiblemechanism could have been an equivalent increase in thetrans-pulmonary pressure both during incentive spirometry ingroup $A$ and stacked breathing in group $B$ because of whichthere was no statistically significant difference between thegroups for lower zones. This study has many limitations. Length of hospital stay and the medications varied for eachindividual. BMI was not considered which could haveinfluenced the study because if the patient is obese the chestexpansion is restricted. Small number of subject with unilateral pleural effusion was taken in each group, whichdecreases the applicability to whole populations. There was nomethod undertaken in the study to ensure that the subjectperform regular exercises without fail on a regular basis asthere was no reliable and valid method found to ensure theirregular follow up or to keep a check on their compliance toexercise.

\section{CONCLUSION}

The study concludes that both the techniques were equallyeffective in improving the chest expansion in subjects with unilateral pleural effusion.

\section{Conflicts of interest: None}

\section{REFERENCES}

[1]. Hough Alexandra 2001. Physiotherapy in respiratory care. An evidence based approach to respiratory and cardiac management $3^{\text {rd }}$ ed. P.98. 
[2]. Gupta A.K, berry, M. Ventriculo-peritonial shunt presenting with recurrent pleural effusion; Report a new complication. Pediatric Radiology. 1994;24(2). Dio: 10.1007/bf02020178. ISSN 0300449. PMID 8078722. S2CID 29-16135.

[3]. Jardins, T.D., Burton, G.G. clinical manifestation and assessment of respiratory disease. $5^{\text {th }}$ ed. p. 319323.

[4]. McGrath, E.E., Anderson, P.B. Diagnosis of pleural effusion: A systematic Approach. American journal of critical care.2001; March; 20(2).

[5]. De Menezes Lyra R. A modified outer cannula can help thoracentesis after pleural biopsy". Chest. 1997;112(1):296. Doi; 10.1378/ chest. 112.1.296. PMID 9228404.

[6]. Galagan et al. color atlas of body fluids.CAP press, Northfield, 2006

[7]. Light RW, Girard WM, Jenkinson SG, George RB, Parapneumonoc effusion. A.M J Med 1980; 69:50712.

[8]. Squire, LUCY Frank; Novelline, Robert A. (2004). " Squire fundamental of radiology ". Cambridge: Harvard University Press. PP. 132-3. ISBN 0-67401279-8.

[9]. Downie, P.A. 1987.Cash's textbook of chest, heart and vascular disorders for physiotherapy. $4^{\text {th }}$ ed. P. 533.

[10]. Vikram, M., Leonard, J.H. and Kamaria, K. Chest Wall Stretching Exercise as an Adjunct Modality in Post Operative Pulmonary Management.2012; Mar 4.
[11]. Ferreira, G.M., Haeffner, M.P, Barreto, S.S., Dall'Ago, $P$. Incentive spirometry with expiratory positive airways pressure brings benefits after myocardial revascularization. 2010 Feb; 94(2):230-5, 246-51, 233-8.

[12]. Baker, W.L., Lamb, V.J., Marini, J.J. Breathstacking increases the depth and duration of chest expansion by incentive spirometry. 1990 Feb; 141(2):343-6.

[13]. Agostini, P. and Singh, S. Incentive spirometry following thoracic surgery: what should we be doing? 2009 Jun; 95(2):76-82. Epub 2009 Mar 3.

[14]. Vikram, M., Leonard, J.H. and Kamaria. Chest Wall Stretching Exercise as an Adjunct Modality in Post Operative Pulmonary Management. Mar 4.2012.

[15]. Kakizaki, F., Shibuya, M., Yamazaki, T., Yamada, M., Suzuki H. and Homma, I. Preliminary report on the effects of respiratory muscle stretch gymnastics on chest wall mobility in patients with COPD. Respir Care, 1999;44:409-14.

[16]. Milojeviæ, M., Kuruc, V.Laser biostimulation in the treatment of pleurisy. 2003 Nov-Dec; 56 ( 11-12):516-20.

[17]. AARC Clinical Practice Guideline; Reprinted from the December 1991 issue of Respiratory Care [Respir Care 1991;36(12):1402-1405.

How to cite this article: Minhaj Tahir, Tahzeeb Fatima, Devendra Trivedi, Manjit Kumar. Chest Mobility Exercise with Staked Breathing Versus Chest Mobility Exercises with Incentive Spirometery On Chest Expansion with Pleural Effusion Patient: A Comparative Study. Int J Physiother Res 2021;9(4):3949-3953. DOI: 10.16965/ijpr.2021.155 